\title{
THE USE OF COMPUTER WORKSTATIONS IN THE STUDY OF ENVIRONMENTAL GEOLOGY: INTEGRATION OF GEOPHYSICAL AND GEOLOGIC DATA
}

A. Martinez ${ }^{1}$, T. Carr ${ }^{1}$, R. Black ${ }^{2}$, H.R. Feldman ${ }^{1}$, J.F. Hopkins ${ }^{1}$, A.J. Feltz ${ }^{1}$, D.R. Collins ${ }^{1}$, J. Doveton $^{1}$ and N.L. Anderson ${ }^{3},{ }^{1}$ Kansas Geological Survey, Lawrence, KS 66044;

${ }^{2}$ Department of Geology, University of Kansas, Lawrence, KS; and ${ }^{3}$ Department of Geology \& Geophysics, University of Missouri-Rolla, Rolla, MO

\begin{abstract}
Geophysical techniques coupled with the modern computer workstation have not been widely used in environmental geology. The Kansas Geological Survey is investigating the application of the computer workstation in a number of projects underway that involve environmental questions and problems associated with salt dissolution. The computer workstation provides an efficient approach to integrate geologic and geophysical interpretations of the shallow subsurface. In addition to modification of available techniques originally developed for computer-aided exploration and development of hydrocarbons, several new applications unique to shallow subsurface characterization are being developed. All applications are capable of addressing environmentally-related questions at various scales from regional aquifer mapping to site specific characterization.
\end{abstract}

Various geophysical and geologic methods have been used to image the shallow subsurface $(0-100 \mathrm{~m})$. These methods used in conjunction with a modified computerized interpretation system include high-resolution seismic reflection (2-D and 3-D), vertical seismic profiling (VSP), ground-penetrating radar (GPR), and color image transformation and treatment of the transformed wireline log data as "seismic" traces (pseudo-seismic). The computer workstation approach allows efficient, detailed and integrated studies to be performed at these sites.

Examples from throughout Kansas involving a variety of environmental questions and problems associated with salt dissolution are used to illustrate the utility of using the computer workstation in the study of environmental geology.

KEY WORDS computer workstations, environmental geology, Permian salts, geophysical data

\section{INTRODUCTION}

Computer workstation-based interpret ational software has revolutionized how geophysical, geologic and engineering data are interpreted by the petroleum industry. Major computer technologies, including near super-computing capabilities on inte ractive desktop workstations, complex networking, high capacity mass storage devices, 3-D visualization software, and large digital databases, have radically changed the petroleum industry's approach to expl oration and development. Emphasis within the petroleum industry is now on powerful interpretational software that minimizes $\mathrm{re}$ petitive tasks, integrates technologic disc iplines, maximizes analysis and simulation, and increases the number of mistakes (dry holes) that are drilled on the desk instead of in the field. These powerful computeraided interpretational systems have yet to 


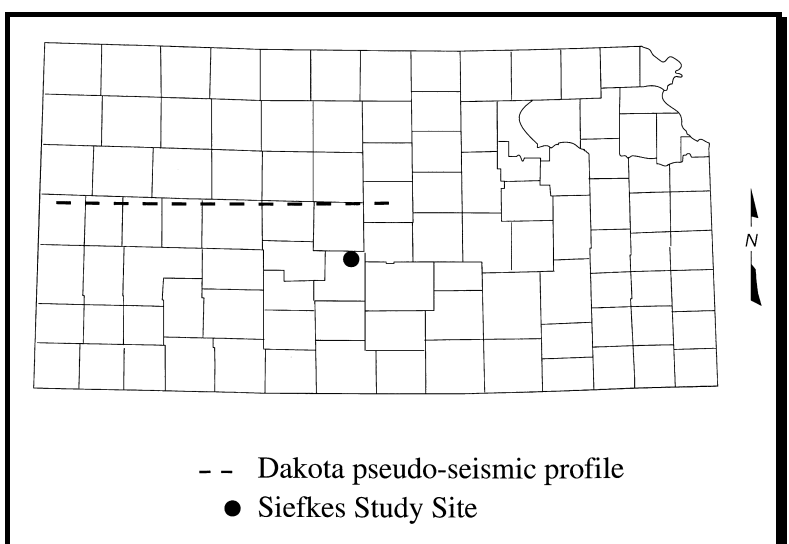

Figure 1. Location of the Siefkes Study Site and the selected pseudo-seismic line from the Dakota Study Area in Kansas.

be widely used by environmental profe ssionals.

Adequate understanding of heterogeneities of near subsurface geology is an important component to improved site investigations, avoidance of excess spending and ineffe ctive remediation. Environmental investig ations have focused on the point data obtained from the drill rig. Point data are often inadequate for understanding preferential flow pathways and variations in relative permeability. Near-surface computer-aided geophysical and geologic methods are another way to image the subsurface. Application of computer-aided visualization and analysis systems in conjunction with the use of near-surface geophysical and ge ologic methods can provide detailed information of subsurface structures that affect fluid flow direction and rate of fluid movement and enhance containment and rem ediation procedures.

This paper presents projects underway in Kansas that involve the application of ge ophysical and geological methods and the computer workstation to a variety of environmental questions and problems associated with salt dissolution. Permian salts present in the shallow subsurface of the central and southern parts of Kansas result in a number of environmental problems ranging from large-scale contamination of entire aquifers to localized dissolution collapse features. Causation is a complex interaction of natural processes and anthropogenic activities (e.g., irrigation and oil field activities). Examples from Kansas illu strate the utility of the computer workstation to perform integrated studies of environmental problems at scales ranging from small-scale site investigation to regional aquifer studies (Figure 1). Data were collected as part of ongoing studies of ground water aquifers in Kansas by the Kansas Geological Survey.

Various geophysical methods were used at several site investigations to image the geology of the shallow subsurface $(0-100 \mathrm{~m})$. These methods include high-resolution seismic reflection (2-D and 3-D), vertical seismic profiling (VSP), and groundpenetrating radar (GPR). These geophys ical methods along with subsurface geologic data are used in conjunction with a computerized interpretation system. The system allows efficient, detailed and integrated studies to be performed at these sites.

In order to undertake a regional aquifer study, a new application of computer workstation-based interpretational software was developed. This application treats transformed wireline log data as "seismic" traces for the purposes of processing, interpretation and display. A color image transformation can combine data from selected wireline logging tools to generate a color coded "crossplot log" for each well. A well-designed transformation can provide an image of the spatial distribution of subsurface lithology or fluids. The transformed image, in either 2-D or 3-D, can be treated on the workstation as "seismic" data, ea sing the data handling burdens through use of computerized techniques designed for interpretation of seismic data.

\section{SMALL- TO MEDIUM-SCALE APPLICATIONS: THE SIEFKES STUDY SITE}




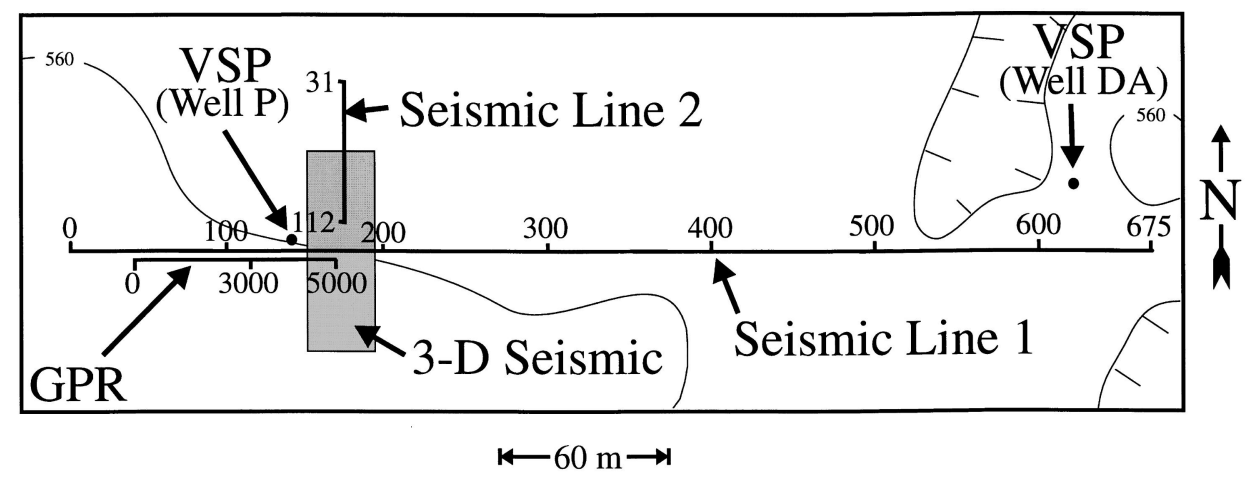

Figure 2. Detail map of the geophysical study at the Siefkes Study Site. The locations of the ground-penetrating radar (GPR) profile, 2-D seismic reflection profiles, 3-D seismic reflection patch and vertical seismic profiles (VSP) are shown.

The Siefkes Study Site is located in central Kansas (Section 27, T21S, R12W, Stafford County). The site is contaminated with a region of salt water intrusion into the fresh water aquifer. Salt water contamination of subsurface fresh water supplies is a serious concern within this area of central Kansas [1]. The main source of fresh water in the region is a near-surface aquifer contained within unconsolidated Quaternary alluvium. Salt-rich waters are upwelling from the Permian bedrock into this overlying all uvium. At the Siefkes Study Site there is a noticeable upwelling of salt-rich waters around an irrigation well late in the pumping season. Salt water contamination reaches a high enough level that crop damage can result.

The Siefkes Study Site is part of the Mineral Intrusion Study Area, a region of intensive study by the Geohydrology Section of the Kansas Geological Survey [2, 3]. Site characterization and ground water mode ling of the Siefkes Study Site were undertaken in order to improve understanding of ground water flow within the area. Two monitoring wells were placed within the proximity of the irrigation well to monitor subsurface salinity levels and provide lithological information. Ground water modeling of the area used information provided by these ground-water monitoring wells. However, the limited control points severely limited site characterization and subsequent ground water modeling.

In order to improve site characterization, a series of geophysical investigations were performed (Figure 2). The geophysical data collected include a ground-penetrating radar profile imaging the very-near surface above the water table, 2-D and 3-D nearsurface seismic reflection data imaging the Permian bedrock surface and deeper rock units, and near-surface vertical seismic profile data used to depth-tie the seismic data with lithological information.

\section{Ground-penetrating radar (GPR)}

A short line $(76 \mathrm{~m})$ of GPR data was a cquired in the vicinity of two wells at the Siefkes Study Site. Data was acquired u sing a GSSI SIR System 8 GPR unit with a $500-\mathrm{MHz}$ transducer. The data were downloaded from the unit and converted into SEGY format for data integration and interpretation within the workstation environment. The vertical (time) and horizontal (distance) scales for GPR data differ considerably from seismic reflection data. B ecause the GPR data length is in nanose conds, rather than milliseconds, it was ne cessary to time-scale the sample interval of the data by a factor of $1 \times 106$ for viewing purposes. The horizontal spacing (CDP) for this data set is approximately $1.2 \mathrm{~cm}$ per CDP point. 


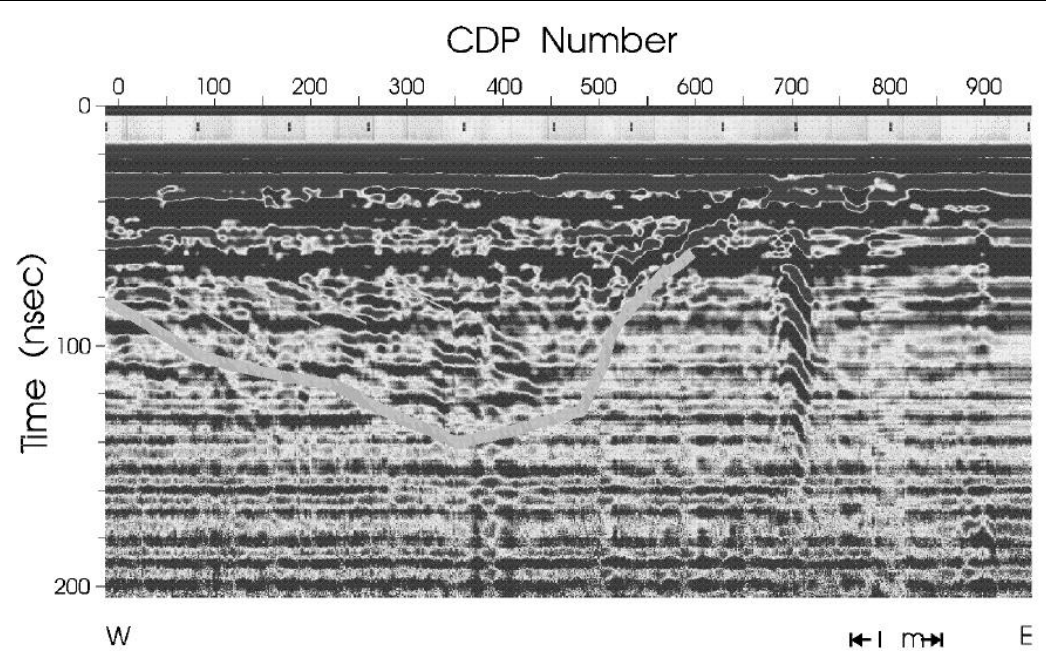

Figure 3. Detailed image of ground-penetrating radar profile across a feature interpreted as a paleo-stream cha nnel. The cut bank, as well as several lateral accretionary bars, are hig hlighted.

Once time-scaled, the GPR data were loaded into the computer workstation and viewed. The GPR data were treated as stacked seismic data, opening up the possibility of using conventional post-stack seismic reflection tools to process the data. Trace balancing and gains were applied in order to give the profile an even appearance and to accentuate anomalies. Other digital processing techniques included bandpass filtering (to remove highfrequency multiple events caused by the water table) and f-k filtering (to reduce hor izontal linear events and accentuate anomalies).

Several features of interest were found along the GPR profile. A portion of the profile over a subsurface feature is interpreted as a portion of a paleo-stream channel, with the interpreted point bar and cut bank highlighted (Figure 3). Also seen is a diffraction, believed to be caused by the remains of a shot point station from the seismic data collected in the area. The GPR data indicates that the very-near su rface is relatively laterally and vertically he terogeneous in nature (Figure 3 ). This he terogeneity can greatly affect the infiltration of fresh water from the surface into the subsurface and should be incorporated to develop accurate models of aquifer recharge.

\section{2-D and 3-D near-surface seismic reflection and vertical seismic profiling}

Near-surface 2-D seismic reflection profiles, a 3-D seismic reflection patch, and two ve rtical seismic profiles were collected at the Siefkes Study Site. Seismic Line One images the subsurface between the two ground-water monitoring wells (wells $P$ and DA on Figure 2). Seismic Line Two is perpendicular to Line One and is located near well $P$. The single-fold 3-D seismic patch is centered on the two seismic lines in order to maximize velocity information for normal move-out (NMO) corrections. The two vert ical seismic profiles (VSP) were collected at wells $P$ and DA. The VSP data provided basic velocity functions for the seismic data interpretation process and, more importantly, time-depth information to depth-tie the seismic reflection data to known subsurface stratigraphic units. The vertical seismic profile trace from well $P$ in relation to gamma-ray and conductivity logs is shown in Figure 4. 


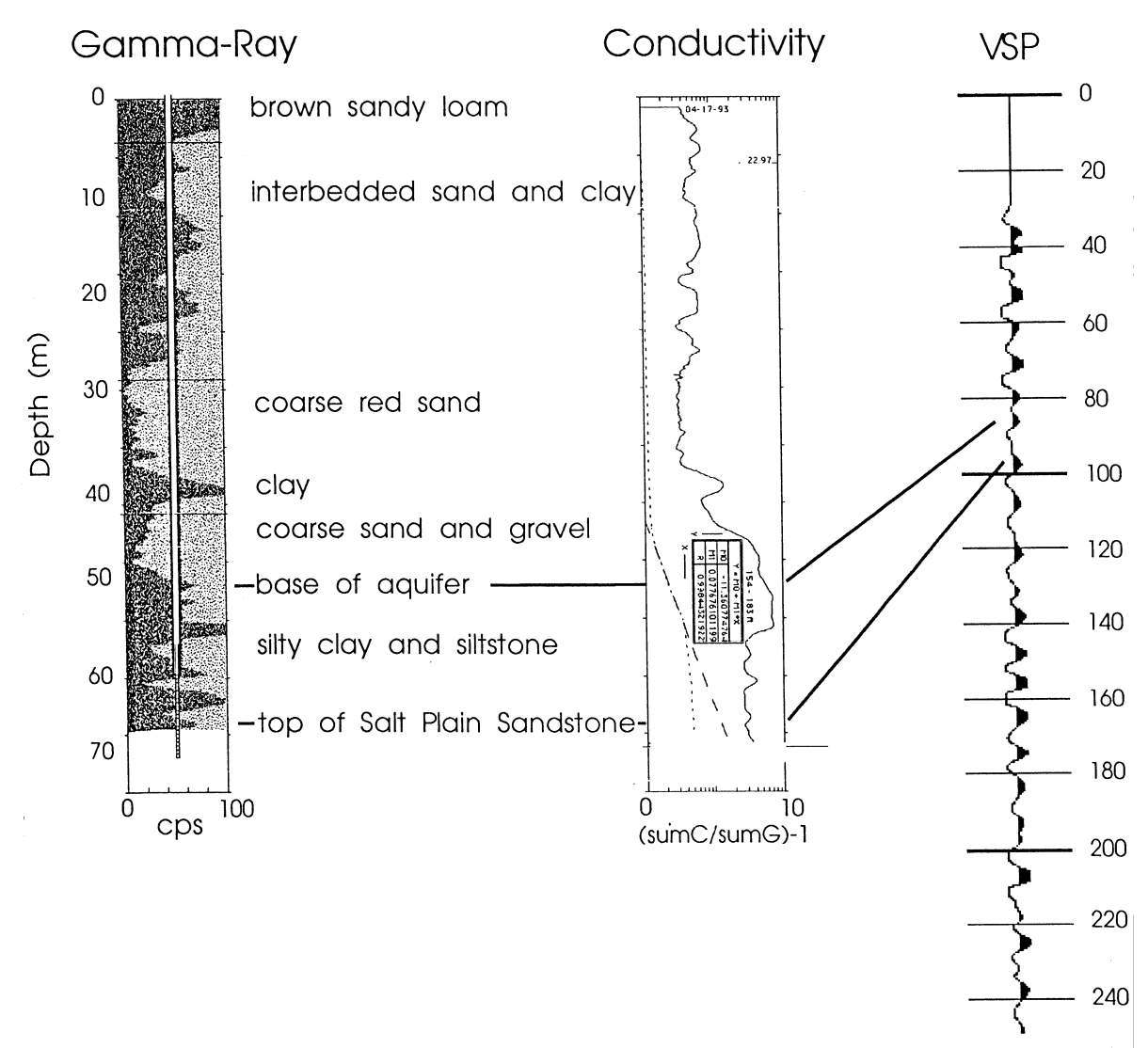

Figure 4. Vertical seismic profile trace from well $P$ shown in relation to gamma-ray, conductivity and lithological information.

All of the 2-D and 3-D seismic data were collected using a downhole 30.06 rifle as a source. The end of the rifle barrel was placed approximately $0.6 \mathrm{~m}$ beneath the ground surface and a bullet was fired into the ground. Two common shot records were gathered and stacked at each shot location before digital archiving. Receivers consisted of three $40-\mathrm{Hz}$ vertical ge ophones placed in an array, with receiver take-out spacings of $1.2 \mathrm{~m}$. The data were recorded using a Bison 9048 seismograph with a $0.5 \mathrm{msec}$ sample rate. Data proces sing for the seismic reflection data was performed with the SierraSEIS processing package and consisted of standard trace editing, first arrival muting, air-wave and ground roll muting, bandpass filtering, $f-k$ filtering, velocity analysis, NMO-corrections and stacking. The seismic reflection data were trace-balanced and loaded into the computer workstation for interpretation after stacking.

The VSP data were collected using an a ccelerated weight drop source. The receiver consisted of a three-component downhole geophone. The data were recorded using a Bison 9024 seismograph with a $0.25 \mathrm{msec}$ sample rate. Five common shot records were gathered and stacked at each receiver depth location before digital archiving. Data processing for the VSP data co nsisted of trace sorting, trace editing, wavefield separation, coherency filtering, deco nvolution, static correcting and stacking. The resulting traces were used to depth-tie the seismic reflection data at the two ground water monitoring wells. Reflections from the base of the aquifer $(51 \mathrm{~m})$, and tops of the Salt Plain $(69 \mathrm{~m})$, Harper (104 m), and Stone Corral $(195 \mathrm{~m})$ formations are seen 


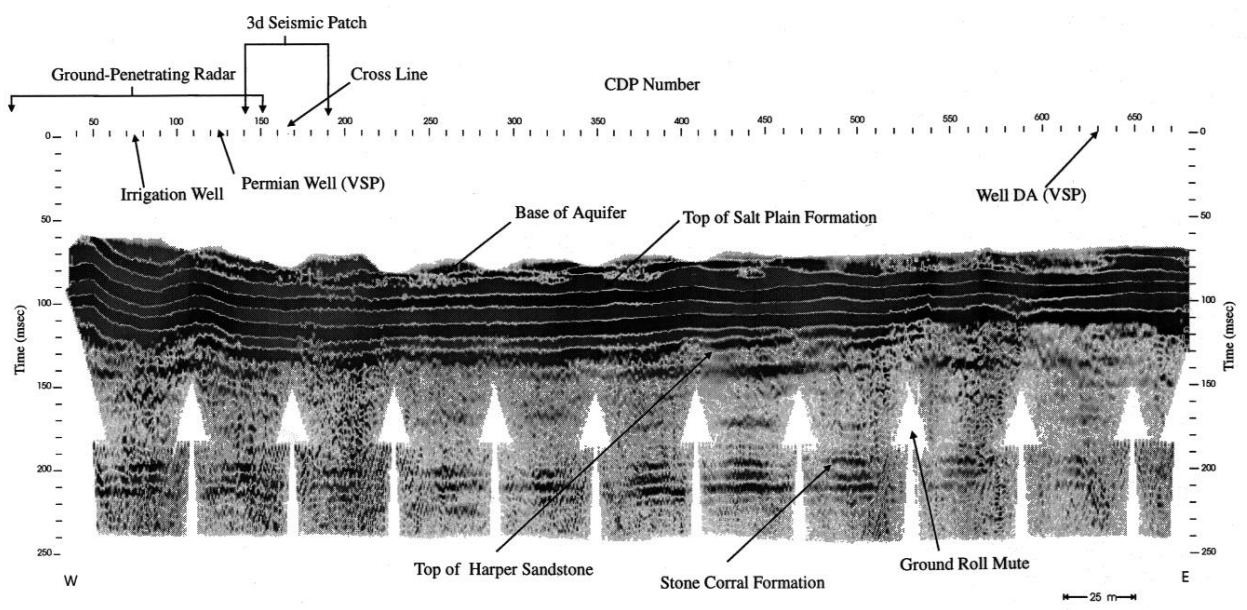

Figure 5. Greyscale display of Seismic Line One. Interpreted horizons include the base of the aquifer, the top of the Salt Plain Formation, the top of the Harper Formation, and the top of the Stone Corral Formation.

on Seismic Line One (Figure 5). All depths refer to the depths of reflectors at well $P$ as determined by the VSP.

Seismic reflection imaging of the subsurface reveals previously unknown subsurface structure at the Siefkes Study Site. The area between wells $P$ and DA appears to be a Permian structural low in the subsurface. In addition, the reflection from the contact between the base of the Salt Plain Formation and the top of the Harper San dstone Formation disappears on the eastern portion of Seismic Line One. This is inte $r$ preted as destructive interference between the second peak of the Salt Plain reflection doublet and the first peak of the Harper Sandstone doublet as a result of stratigraphic thinning of the interval between the two units. The well data was insufficient to image the structural and stratigraphic variations at the Siefkes site. Such subsurface heterogeneities may be hydrologically significant in influencing the movement and concentration of Permian salt-rich brines at the site.

The single-fold near-surface 3-D seismic reflection data were collected in an attempt to determine the feasibility of small-scale 3$D$ seismic methods in near-surface studies. The 3-D seismic reflection data have a bin size of $0.6 \mathrm{~m} \times 1.2 \mathrm{~m}$. Although the data are only single fold and encompass a relatively small area, useful information was obtained once the data were loaded into the computer workstation and interpreted. Interpretation of the 3-D seismic reflection data was greatly enhanced by the data i maging capabilities of the workstation. Vert ical and horizontal data slices were taken of the data (Figures $6 \& 7$ ). Horizon tops were selected using these data slices. The resul ting horizon picks were displayed as a 3-D volume for visualization purposes (Figure 8). The reflections from the base of the aquifer, the top of the Salt Plain Formation, and the Stone Corral Formation are visible on vertical slices. The reflection from the top of the Harper Sandstone is very faint and is visible on only a few vertical slices. The time-slice through the Salt Plain Formation reflection shows that the reflection has a slight dip to the south-east, sugges ting that the Salt Plain Formation may dip slightly to the south-east in the Siefkes area. The experimental 3-D patch could be significantly improved with higher fold. The higher fold would provide greater velocity control and more reflection continuity for the 3-D data. 


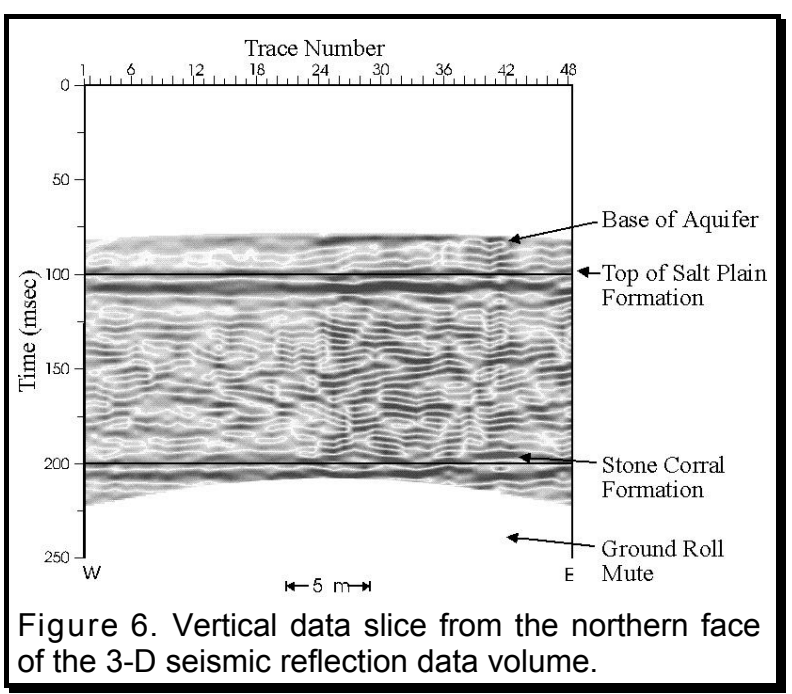

\section{A LARGE-SCALE APPLICA- TION: THE DAKOTA STUDY AND THE PSEUDO- SEISMIC APPROACH}

As near-surface ground water sources become more scarce, the Cretaceous Dakota aquifer is becoming an important potential source of ground water for western Kansas. A study of the Dakota aquifer is underway in order to develop a better assessment of water-resource potential and planning needs of the aquifer [4]. The Dakota aquifer is composed of irregularly distributed sandstones of the Dakota and Kiowa formations and Cheyenne Sandstone. An understanding of the aquifer's lateral extent, vertical thickness and overall capacity across western Kansas is important for developing well-spacing requirements and sound resource management. The Dakota aquifer study mainly involves using existing well log information to achieve these goals. Because the study encompasses a large area (approx. 125,000 $\mathrm{km}^{2}$ ) and a large number of wells, alternative methods of macro- scale well log analysis were exa mined and a method designated as pseudoseismic profiling was developed [5].

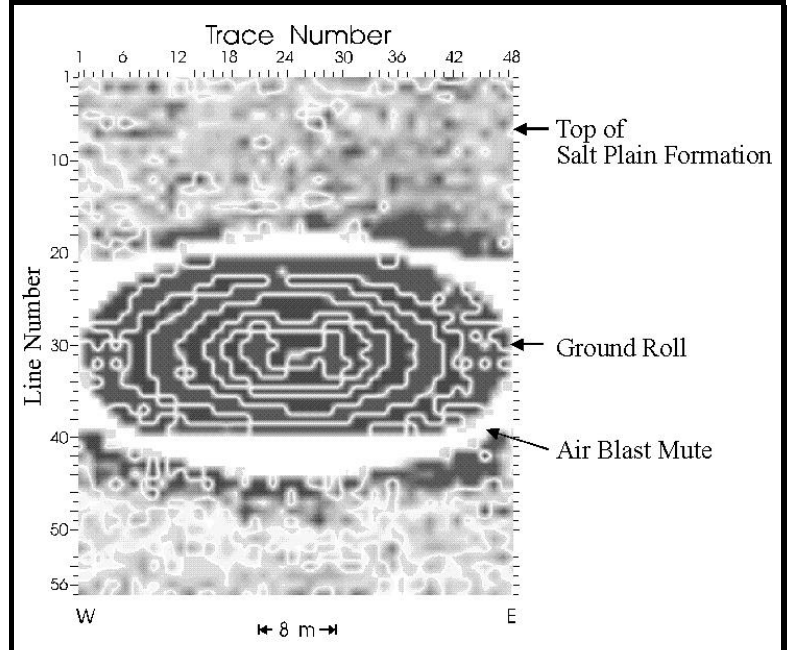

Figure 7. Horizontal data slice taken at $95 \mathrm{msec}$ from the 3D seismic reflection data volume. The $r e-$ flection from the Salt Plains Formation is intersected by this data slice.

\section{Pseudo-seismic profiling}

Stratigraphic interpretation from wireline logs is typically drawn from multiple log traces or from crossplots of log data. Both techniques can readily depict vertical changes in lithology or reservoir quality, but lateral relationships are not easily visua Iized. Significant improvement in the ge ologic interpretation of wireline log data can be achieved through color image transformation and treatment of the transformed data as "seismic" traces for the purposed of processing, interpretation and display [6]. Such transforms can combine data from porosity, gamma and density tools genera ting a color coded "crossplot log" for each well. A well-designed color transformation of wireline log data from multiple wells maximizes both spatial and compositional information content and provides a readily interpretable image of the subsurface geo logy. The transformed image, in either 2-D or 3-D, can be treated as "seismic" data, easing the data-handling burdens through the use of computerized techniques designed for interpretation of seismic data.

The pseudo-seismic approach to stratigraphic interpretation is based on the observation that wireline well logs resemble 


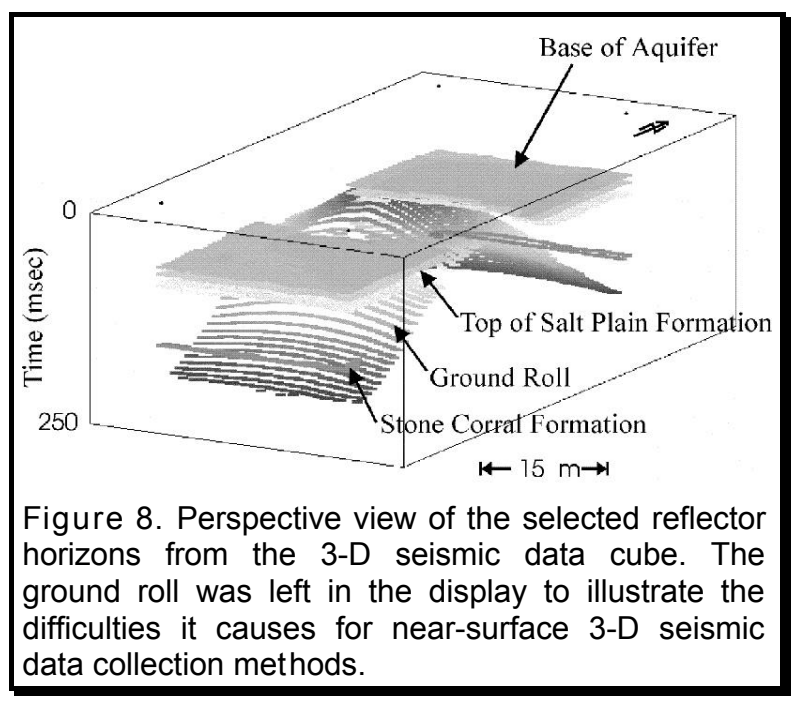

seismic traces in many respects. Both seismic data and wireline log data are si mple $x-y$ series, one in the amplitude-time domain and the other in the amplitudedepth domain. Wireline well logging tools record various rock properties and output these data as a depth series. Ultimately, the goal of seismic-style processing is to approach on a trace-by-trace basis the resolution of geophysical well logs.

A pseudo-seismic profile provides a simple representation of Permian through Cretaceous rocks of western Kansas based solely on gamma-ray logs (Figure 9). More than 150 wells were converted to SEGY format and loaded into the workstation as seismic traces. Trace spacing was selected to be approximately $1.6 \mathrm{~km}$, and wells were assigned to the nearest trace. Areas of sparse well control are represented by blank traces. The section can be interpreted and displayed using all the tools available within the workstation environment. Using just rudimentary workstation tools results in a startling increase in inte $r$ pretation speed. Using the zoom, datum, and manual and auto-picking tools, the profile was interpreted in a few hours. Interpretations were subject to continuous verification by examination of the data set as a whole. The display capabilities of workstation-based interpretational software increases the power of the visualization as compared to traditional computer-assisted wireline log cross-sections. Features such as truncation of individual beds within the Permian by the Cretaceous unconformity, the effect of the dissolution of Permian salt on localizing deposition of overlying Che yenne-Dakota fluvial sands, and normal faulting on the western margin of the Ce ntral Kansas Uplift are readily apparent (Figure 9). The zoom and datum capabil ities of the workstation can be used to map truncation, onlap and downlap of individual "beds" within specific stratigraphic units. In terms of vertical resolution, pseudo-seismic data can surpass seismic data, as vertical resolution is limited only by the resolution of the logging tool and the digital data.

\section{CONCLUSIONS}

In order to improve site investigations, environmental professionals need to consider application of near-surface geophysical and geologic methods coupled with the visual ization and analysis power of computer workstation-based interpretational systems. Improved understanding of the subsurface geology is an important consideration for development of adequate sampling strat egies and the design of workable remediation systems.

Computer workstation-based interpret ational software provides the tools to handle mass quantities of data for improved site characterization. Changes in computer technologies have allowed integration of once discrete professional skills and technologies. Major computer technologies include near super computing capabilities on interactive desktop workstations, complex networking, high capacity mass storage devices, 3-D visualization software, and large digital databases. Engineers, geol ogists, geophysicists and other environmental professionals will more likely meet at a computer terminal than at a confe $r$ ence table and communicate over the ne twork rather than in formal meetings. Work- 


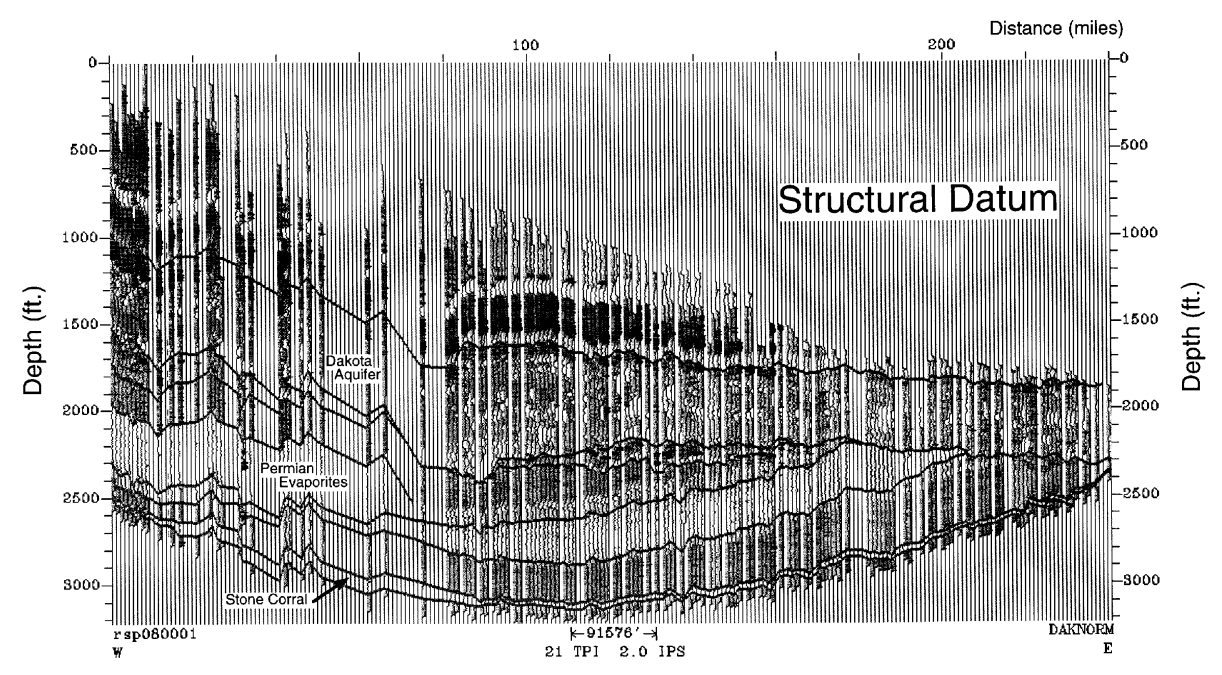

Figure 9. Structurally-datumed pseudo-seismic profile of gamma-ray logs showing the Dakota aquifer. Light gray tones correspond to low gamma-ray values associated with sandstones, limestones and evaporites. Darker shades correspond to high gamma-ray values from shales. This profile was constructed using gamma-ray logs from over 150 wells. (modified from [4])

stations can radically change the approach to environmental geology by integrating technology across disciplines (Figure 10). Teams will become more common-place. No longer can each discipline work on its piece of the problem use a colored pencil to put the results on a piece of paper or map, pass the results along to the next discipline, and be done with it. Large volumes of data should be accessible to and used by all the members of a team, permitting reiteration in the constant process of site characterization, sample design, remediation and policy development.

As illustrated above, near-surface ge ophysical methods are capable of imaging the shallow subsurface and determining the geometries of subsurface structures that affect direction and rate contaminant flow. Various two-dimensional profiles and threedimensional volumes of environmentaloriented geophysical data along with ge ologic point data from wells can be brought together for an integrated interpretation within the computer workstation environment. The color display and post-stack processing capabilities of the workstation greatly enhance data interpretation, allo wing small-scale to large-scale lateral nearsurface heterogeneities of the alluvium and deeper bedrock structures to be succes sfully imaged and interpreted.

A copy of this paper along with color ve rsions of the figures are available on the Kansas Geological Survey's web site (http://www.kgs.ukans.edu) on the Petroleum Research Section's recent publications page (http://crude1.kgs.ukans.edu /cgi-bin/wwwwais.pl).

\section{ACKNOWLEDGMENT}

Landmark Graphics Corporation provided the interpretation and analysis software under an educational grant to the Kansas Geological Survey and the University of Kansas.

\section{REFERENCES}

1. R.W. Buddemeier, R.S. Sawind, D.O. Whittemore and D.P. Young, Salt Contamination of Ground Water in SouthCentral Kansas, Kansas Geological 


\section{Environmental Geology Technology Integration}

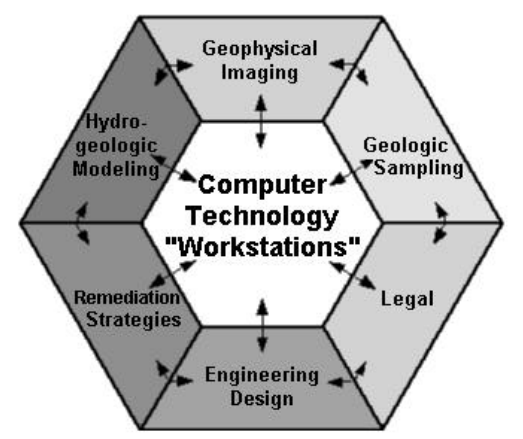

Figure 10. Integrated team approach to environmental geology and the central role of computer technology in technology integration.

Survey, Public Information Circular 2, 1995.

2. D. Young, G.H. Garneau, R.W. Buddemeier, D. Zehr and J. Lanterman, Saltwater Elevation and Variability in the Great Bend Prairie Aquifer, SouthCentral Kansas, Kansas Geological Survey Open-File Report 93-55, 1993.

3. R.W. Buddemeier, G. Garneau, J.S. Healey, M.A. Sophocleous, D.O. Whittemore, D. Young and D. Zehr, The Mineral Intrusion Project: Report of Progress During the Fiscal Year 1993, Kansas Geological Survey Open-File Report 93-23, 1993.

4. P.A. Macfarlane, J.H. Doveton, H.R. Feldman, J.J. Butler, Jr., J.M. Combes and D.R. Collins, Aquifer/Aquitard Units of the Dakota Aquifer System in Kansas: Methods of Delineation and Sedimentary Architecture Effects on Ground Water Flow and Flow Properties, Jou rnal of Sedimentary Research, B64 (1994) 464-480.

5. T.R. Carr, J. Hopkins, H. Feldman, A. Feltz, J. Doveton and D. Collins, Transforms of Wireline Logs as Pseudo-Seismic Traces, UserNet
Technical Newsletter, Landmark Graphic Corporation, Houston, TX, 1995.

6. D. Collins and J. Doveton, Color Images of Kansas Subsurface Geology from Well Logs, Computers and Geosciences, v. 12, 1986. 